\title{
Electrochemical performance and computational analysis of an Al-based battery system using a cathode of graphene obtained from processed expandable graphite
}

\author{
Rajesh Thomas, ${ }^{\dagger *}$ Shashikant P. Patole, ${ }^{\dagger}{ }^{\dagger}$ Pedro M. F. J. Costa ${ }^{\dagger *}$
}

${ }^{\dagger}$ King Abdullah University of Science and Technology, Physical Science and Engineering

Division, 23955-6900 Thuwal, Saudi Arabia

" Department of Physics, Khalifa University of Science and Technology, P.O. Box 127788,

Abu Dhabi, United Arab Emirates

- Supporting Information

*E-mail: thomasphy@gmail.com ; pedro.dacosta@kaust.edu.sa; Tel.: +966-128084453 


\begin{abstract}
The electrochemical storage of aluminum in graphitic electrodes is a topic of much interest in the search for alternative battery systems. Here, we show that an Al-based battery can be realized using a cathode assembled with graphene flakes obtained from processed expandable graphite. When compared to pristine graphite (in this work, with $45 \mathrm{mAh} / \mathrm{g}$ at a current density of $214 \mathrm{~mA} / \mathrm{g}$ ), the capacity and cycle life performance are notably increased by the use of the graphene flakes (172 mAh/g, at $214 \mathrm{~mA} / \mathrm{g}$, after 100 cycles). The location and persistence of the charged choloraluminate species in the carbon materials was experimentally analyzed and complemented with computational modeling. Accordingly, and besides intercalation, grafting of the Al-species onto the graphene layers was identified as a possible mechanism that enhanced the performance of the processed expandable graphite cathodes. Such a phenomena would make the electrode more conductive and introduce a path for charge storage on its surface (akin to faradaic supercapacitors).
\end{abstract}




\section{Introduction}

Decades after their first commercial deployment, [1-3] Li-ion batteries continue to be the most popular and technically advanced energy storage device for applications that range from electrical vehicles to consumer goods such as portable computers.[4-7] Despite their success, these batteries are unlikely to represent a feasible option for future large-scale, high capacity applications. Two well-known limitations are short-circuiting of the electrodes (due to the formation of dendrites across the electrolyte) and, more critical, the lack of sufficient geological reserves of lithium to keep up with the expected growing demand.[8] It is thus understandable the continued search for better active elements and electrode materials suitable for energy storage devices [9-11]. In regards to the first, one of the most promising candidates is aluminum ( $\mathrm{Al})$ [12-15]. Besides being abundant in the Earth's crust, the process of mining $\mathrm{Al}$ ores is one of the most cost effective for all those elements known to be active in electrochemical energy storage systems.[16] With respect to its properties, Al has a relatively good electrochemical equivalent $(2.98 \mathrm{Ah} / \mathrm{g})$ and superior volumetric energy density (8.04 $\mathrm{Ah} / \mathrm{cm}^{3}$ ) when compared to $\mathrm{Li}$ (with $3.86 \mathrm{Ah} / \mathrm{g}$ and $2.06 \mathrm{Ah} / \mathrm{cm}^{3}$, respectively). Previous studies have shown that Al-ion batteries have high power density and are safe to operate (e.g. there is no danger of short-circuiting) $[17,18]$ but issues such as cathode disintegration, low cell discharge voltage, capacitive degradation and low cycle life [19-22] remain key challenges for this technology. One other challenge described in early reports was a high corrosion rate, formation of passive oxides and the evolution of $\mathrm{H}_{2}$.[23] This resulted, in great part, from the use of aqueous and organic electrolytes.[24-27] Contrastingly, recent investigations proposed ionic liquids as valid electrolytes which could help overcoming the gas evolution issue and enable better electrochemical performance. [28-30]

Here, we report the comparative performance of two different cathodes for an Al-ion battery system. The active materials used were a conventional graphite powder or graphene 
flakes obtained from processed expandable graphite, both commercially available. The electrochemical performance, along with the intercalation process and structural stability of the cathodes, in charged and discharged states, was evaluated experimentally and modelled from first-principles.

\section{Experimental}

2.1 Materials: graphite $(\mathrm{G})$ powder (Sigma Aldrich, $45 \mu \mathrm{m}$ ) and few-layer graphene flakes (hereafter, EG) were procured. The EG derived from expandable graphite and were produced by Graphene Crystal, a start-up located in KAUST [31]. Generally, the as-received graphene flakes had less than 10 layers, with lateral size of less than $300 \mu \mathrm{m}$ and were well-structured over the full range of the basal plane. For the present work, this powdered material was further processed by a short-period of sonication in n-methylpyrrolidone (NMP) and then dried in air.

2.2 Preparation of the cathode: the slurry was made by mixing $80 \mathrm{wt} \%$ of the active material (G or EG), $10 \mathrm{wt} \%$ of the binder polyvinylidene-fluoride (PVDF) and $10 \mathrm{wt} \%$ of carbon black (conductive agent) in NMP. This mixture was grinded and then subjected to continued stirring for 24 hours. The resulting slurry was used to coat carbon paper by a doctor blade technique after which it underwent a heat treatment $\left(100{ }^{\circ} \mathrm{C}\right)$ for 12 hours in a vacuum oven.

2.3 Preparation of the electrolyte: a room temperature ionic liquid was made by mixing 1-ethyl-3-methylimidazolium chloride ([EMIm]Cl, 97\%, Sigma Aldrich) and anhydrous aluminum chloride $\left(\mathrm{AlCl}_{3}, 99.999 \%\right.$, Sigma Aldrich) at a ratio of 1.3:1. A pale yellow liquid was obtained.

2.4 Electrochemical measurements: these were done in half-cell configuration using a Swagelok cell. Al foil (125 $\mu$ m thickness, $99.998 \%$, Sigma Aldrich) served as the anode, while the coated carbon paper (bearing $\sim 2 \mathrm{mg}$ of active material) acted as the cathode and the synthesized ionic liquid as the electrolyte. All electrochemical measurements were performed 
in a Biologic VMP3 multichannel workstation. Galvanostatic charge-discharge profiles were carried out using a potential window of $0.2-2.3 \mathrm{~V}$, at current ranging from 100 to $1000 \mu \mathrm{A}$. For cyclic voltammetry, a scanning voltage range of 2.5-0.02 V, at a scan rate of $1 \mathrm{mV} / \mathrm{s}$, was used.

2.5 Materials characterization: X-ray diffraction (XRD) patterns of the cathode materials were recorded using a BrukerD8 Advance diffractometer with a $\mathrm{Cu} \mathrm{K}_{\alpha}$ radiation source $(\lambda=0.15406 \mathrm{~nm})$. The surface morphology was examined with a FEI Nova Nano scanning electron microscope (SEM). Raman spectra were acquired with a Witec alpha 300R confocal imaging system, at laser wavelength of $532 \mathrm{~nm}$. An aberration-corrected FEI Titan ${ }^{3}$ 60-300 transmission electron microscope (TEM), operated at $300 \mathrm{kV}$, was used to take images in transmission or scanning transmission modes. Samples for TEM analysis were prepared by dispersing the electrode material in ethanol, via ultrasonication, followed by drop-casting onto an amorphous carbon-coated $\mathrm{Cu}$ grid. X-ray photoelectron spectroscopy (XPS), employed to characterize the surface chemistry of the electrodes, and was carried out in a Kratos AXIS Supra ( $\mathrm{Al} \mathrm{K \alpha}$ radiation). All binding energies were referenced to the $\mathrm{C} 1 s$ peak $(284.6 \mathrm{eV})$ of the adventitious surface carbon. All synthesis and characterization work was performed in temperature-controlled rooms, at $23 \pm 2{ }^{\circ} \mathrm{C}$.

2.6 Computational methods: First-principles density functional theoretical calculations were carried out with QUANTUM ESPRESSO simulation package.[32] A generalized gradient approximation (GGA) was used for exchange correlation energy of electrons and an ultra-soft pseudopotential was used to represent the interaction between ionic cores and valence electrons.[33, 34] Plane-wave basis with an energy cut off of 40 Ry and a charge density with a cut-off $240 \mathrm{Ry}$ was considered after verifying the convergence criteria. Integration over irreducible Brillouin zone for charge density and total energy was performed with a uniform mesh of $3 \times 3 \times 2$ mesh of $k$ points.[35] Occupation numbers were smeared using MethfesselPaxton scheme [36] with broadening of $0.01 \mathrm{Ry}$. 


\section{Results and discussion}

To understand the differences in electrochemical behavior of electrode materials, the morphology, structure and surface chemistry, in both charged and discharged states, must be analyzed. The morphology of the graphite $(\mathrm{G})$ and the processed expandable graphite (EG) materials is illustrated in Figs. 1a and 1d, respectively. As expected, the G powder contains relatively thick flakes with sharp edges, flat surfaces and lateral size of 5 to $10 \mu \mathrm{m}$. As for the EG material, smaller flakes with thinner cross-sections were observed. Consequence of the exfoliation process, these flakes were corrugated thus their higher likelihood to form networks of pores when integrated in a battery's cathode. Generally, the number of graphene layers in the EG was $<20$ with an interplanar distance of $\sim 0.40 \mathrm{~nm}$ (Fig. S1).

The galvanostatic charge-discharge profiles for the first four cycles of the G and EG half-cells were carried out at a current density of $100 \mu \mathrm{A}(70 \mathrm{~mA} / \mathrm{g})$ and are shown in Figs. 1b and 1e, respectively. The voltage range used was $0.02-2.3 \mathrm{~V} v s \mathrm{Al}^{3+} / \mathrm{Al}$. Surprisingly, the specific capacity of the EG-based electrode $(194 \mathrm{mAh} / \mathrm{g})$ was significantly higher than that of its $\mathrm{G}$ counterpart $(60 \mathrm{mAh} / \mathrm{g})$. For both materials, the average voltage plateau for the discharge process was in the range of $2.0-1.6 \mathrm{~V}$. Although common among Al-ion battery systems [2022] this voltage interval is relatively high meaning that is possible to attain a considerable energy density. Of note, the smaller plateau at $\sim 0.4 \mathrm{~V}$; observed in the discharge cycles of both $\mathrm{G}$ and $\mathrm{EG}$ electrodes, after just a few cycles, this can be due to some side reactions in the electrolyte. In regards to the charging step, a plateau was observed for the EG electrode (at $\sim 0.8 \mathrm{~V}$ and after a few cycles, Fig. S2) but not for the $\mathrm{G}$ one. Irrespective, with continued cycling, the curves stabilized for both electrodes and, overall, little difference was seen in discharging capacity from the first to the tenth cycle (Fig. S2). This observation confirms that, 
for both electrodes, the electrochemical process was entirely reversible.
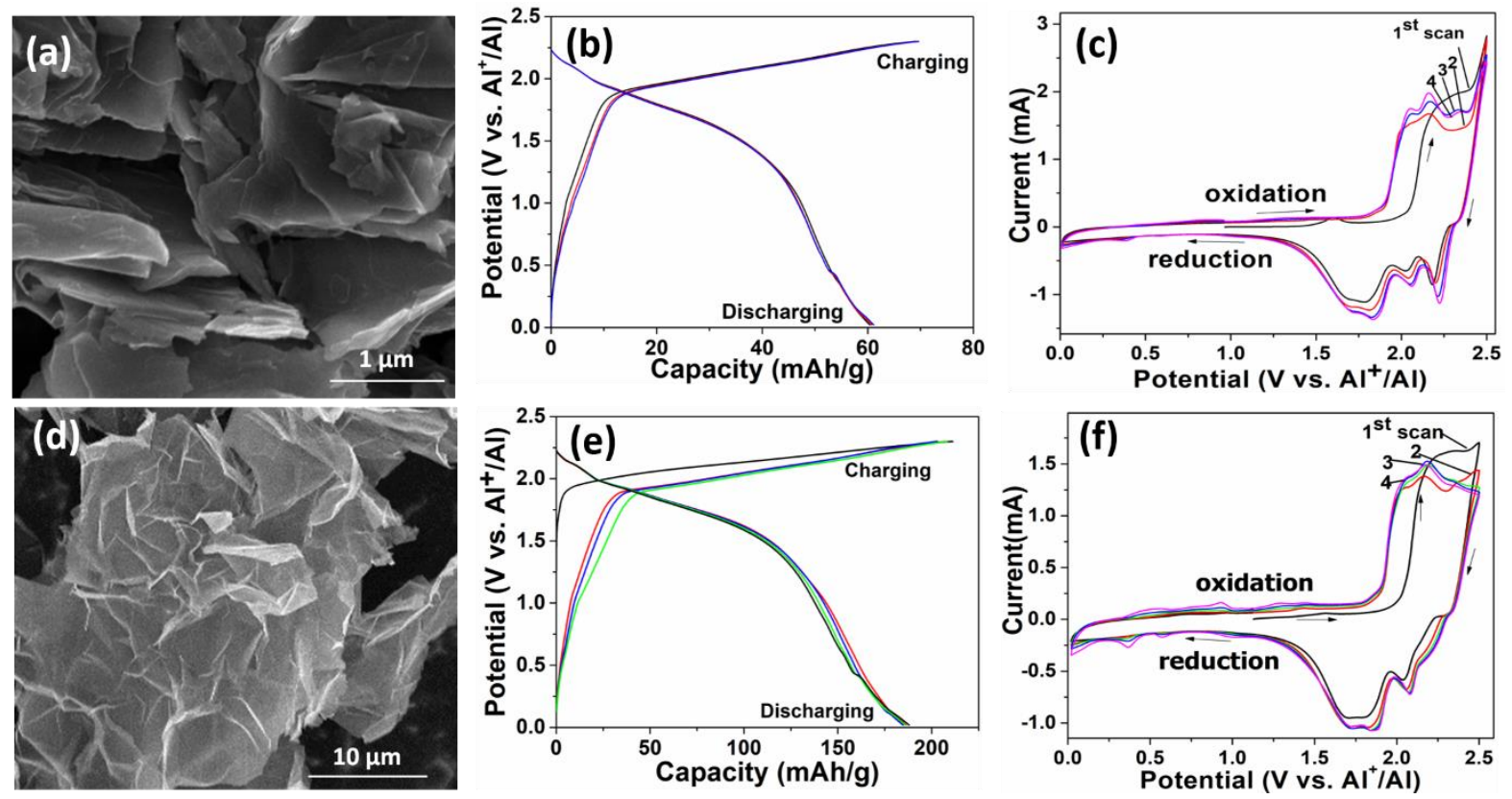

Fig. 1: SEM images, galvanostatic charge-discharge profiles and cyclic voltammetry curves of: $\mathrm{G}$ (a, b and c, respectively) and $\mathrm{EG}$ (d, e and f, respectively).

Cyclic voltammetry (CV) curves for the G and EG electrodes are shown in Figs. 1c and 1f, respectively. For both cases, the first two curves are different from the subsequent ones. This may be due to volume adjustment by the graphene layers, a phenomenon related to the initial intercalation-deintercalation cycles of $\mathrm{Al}_{\mathrm{x}} \mathrm{Cl}_{\mathrm{y}}$ ions. Past the second cycle, the electrochemical reversibility is notable. From the third cycle onwards, the CV curves show oxidation peaks at $2.0 \mathrm{~V}$ and $2.2 \mathrm{~V}$. In the reduction sweep, three peaks are common to the two electrodes, at 1.7 $\mathrm{V}, 1.9 \mathrm{~V}$ and $2.1 \mathrm{~V}$. For the $\mathrm{G}$ electrode, an additional peak at $2.25 \mathrm{~V}$ was observed. The existence of these reversible (Faradaic) peaks is explained by redox reactions taking place during the discharging and charging of the chloroaluminate anions. Generally, it is agreed that the half-reactions of this intercalation process are as follows (here, $n$ is the molar ratio of carbon atoms to graphite intercalated anions):

$$
\mathrm{Al}+7\left[\mathrm{AlCl}_{4}\right]^{-} \rightleftharpoons 4\left[\mathrm{Al}_{2} \mathrm{Cl}_{7}\right]^{-}+3 \mathrm{e}^{-} \quad \text { (anode) }
$$




$$
\mathrm{C}_{\mathrm{n}}+\mathrm{AlCl}_{4}^{-} \rightleftharpoons \mathrm{C}_{\mathrm{n}}\left[\mathrm{AlCl}_{4}\right]+\mathrm{e}^{-} \quad \text { (cathode) }
$$

Taken together, the active potential window for the EG is slightly wider than that for the G electrode - this is consistent with a more extended loading of the Al species in the graphene flakes. Finally, additional peaks were observed at lower potential $(<1.5 \mathrm{~V})$ for the EG. Visible both in the oxidation and reduction steps, these may be due to adsorption of the electrolyte on the surface of the electrode or, eventually, to the formation of an alloy compound with the electrolyte on the electrode surface.
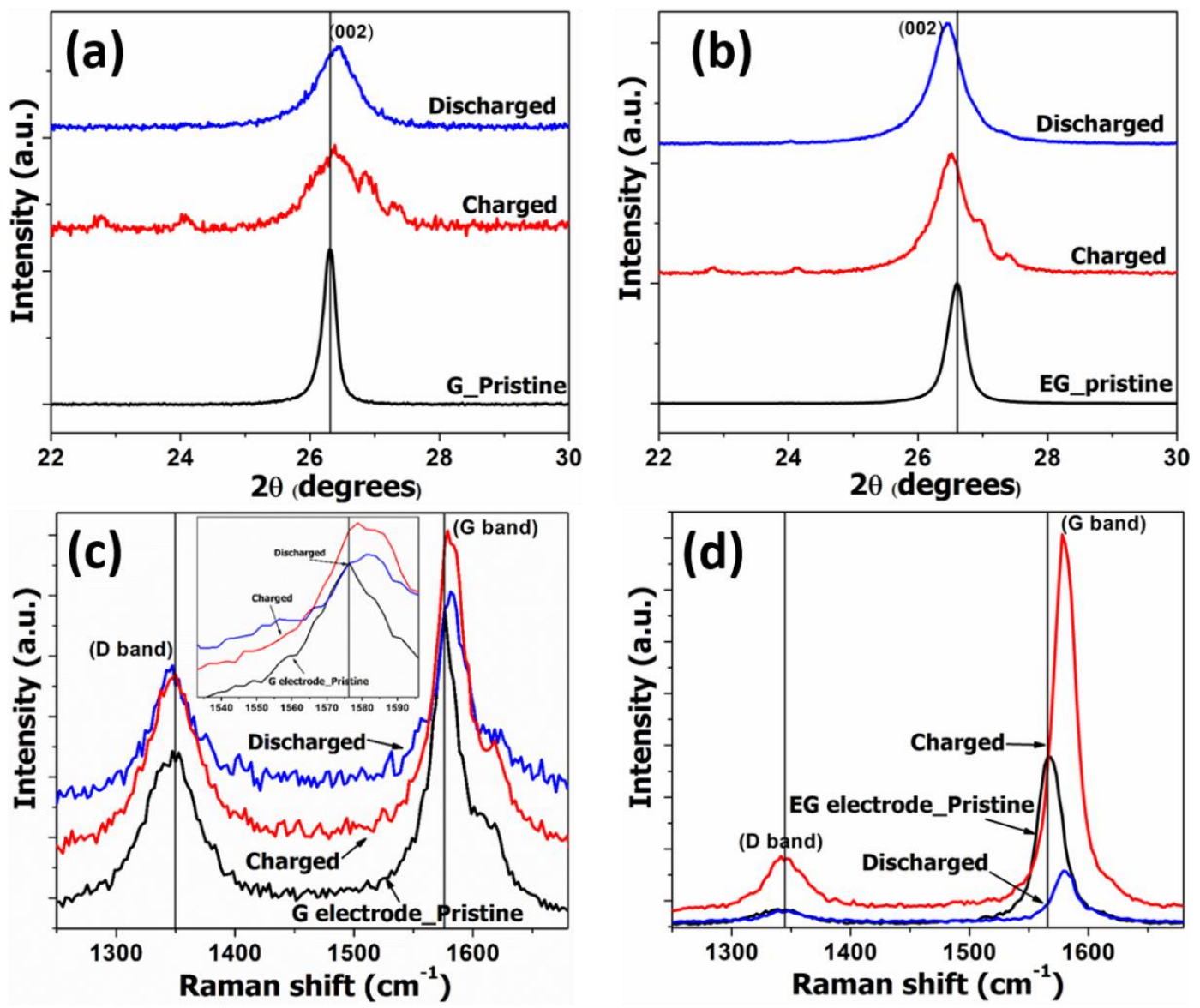

Fig. 2: XRD and Raman spectra of graphite (a and c), separated spectra are shown inset and EG ( $b$ and d) for pristine and after the first charge-discharged conditions.

The structural analysis of the graphitic electrodes was done with powder X-ray diffraction (XRD) and Raman spectroscopy. The XRD pattern of the $\mathrm{G}$ material in its pristine, charged and discharged states are shown in Fig. 2a. Immediately after the first charging, the (002) peak, 
initially at $2 \theta=26.3^{\circ}$, shifted slightly $\left(2 \theta=26.4^{\circ}\right)$ whilst its full-width-at-half-maximum (FWHM) increased from $0.25^{\circ}$ to $0.80^{\circ}$. After discharging, the (002) peak was at $2 \theta=26.5^{\circ}$ but its FWHM remained similar to that in the charged state - likely due to the presence of trapped intercalant species. As for the EG electrode, it showed some interesting structural variations in the pristine, charged and discharged states (Fig. 2b). The (002) peak for the pristine EG was at $2 \theta=26.6^{\circ}$, with a FWHM of $0.34^{\circ}$. These figures are larger than the analogous peak of the $\mathrm{G}$ material and can be justified by the corrugation and smaller size of the EG flakes (cf. Figs. 1a and 1d). After the first charge cycle, the (002) peak shifted leftwards $\left(26.5^{\circ}\right)$ and broadened. While discharging, the (002) position remained at $2 \theta=26.5^{\circ}$. A couple of shoulder peaks on (002) and transient peaks at $<25^{\circ}$ were identified in the charged state for both electrodes (see details in Fig. S3). These were attributed to aluminum oxide $\left(\mathrm{Al}_{2} \mathrm{O}_{3}, \mathrm{ICDD}\right.$ 04-016-7505). It is possible that the oxide formed after the atmospheric exposure of the charged electrodes during their transport to the XRD equipment. Several groups have identified this issue and suggested enveloping the material in scotch tape [37, 38]. Notwithstanding, these peaks were absent in the discharged electrodes.

The Raman spectra of the $\mathrm{G}$ active material in its pristine, charged and discharged states are shown in Fig. 2c. Looking at the $G$-band, there is a shift, upon charging, from $1576 \mathrm{~cm}^{-1}$ to $1582 \mathrm{~cm}^{-1}$. After discharging, the intensity maximum remains at $1582 \mathrm{~cm}^{-1}$. As for the $D$-band, it remains constant throughout, at $1345 \mathrm{~cm}^{-1}$. In the EG electrode, the first charging led to a larger $G$-band shift $\left(15 \mathrm{~cm}^{-1}\right)$, which remained after discharging (Fig. $2 \mathrm{~d}$ ). Just as in the previous case, the $D$-band did not move. The response of both electrodes to the charge-discharge process is similar with the constant $D$-band position and a shift in the $G$-band, this one possibly due to trapped $\mathrm{Al}_{\mathrm{x}} \mathrm{Cl}_{\mathrm{y}}$ species. Interestingly, while the $2 \mathrm{D}$-band maximum was constant (at $2695 \mathrm{~cm}^{-}$ ${ }^{1}$ ) for all states of the $\mathrm{G}$ electrode, it changed for the EG material with charging (by $24 \mathrm{~cm}^{-1}$, Fig. S4). 

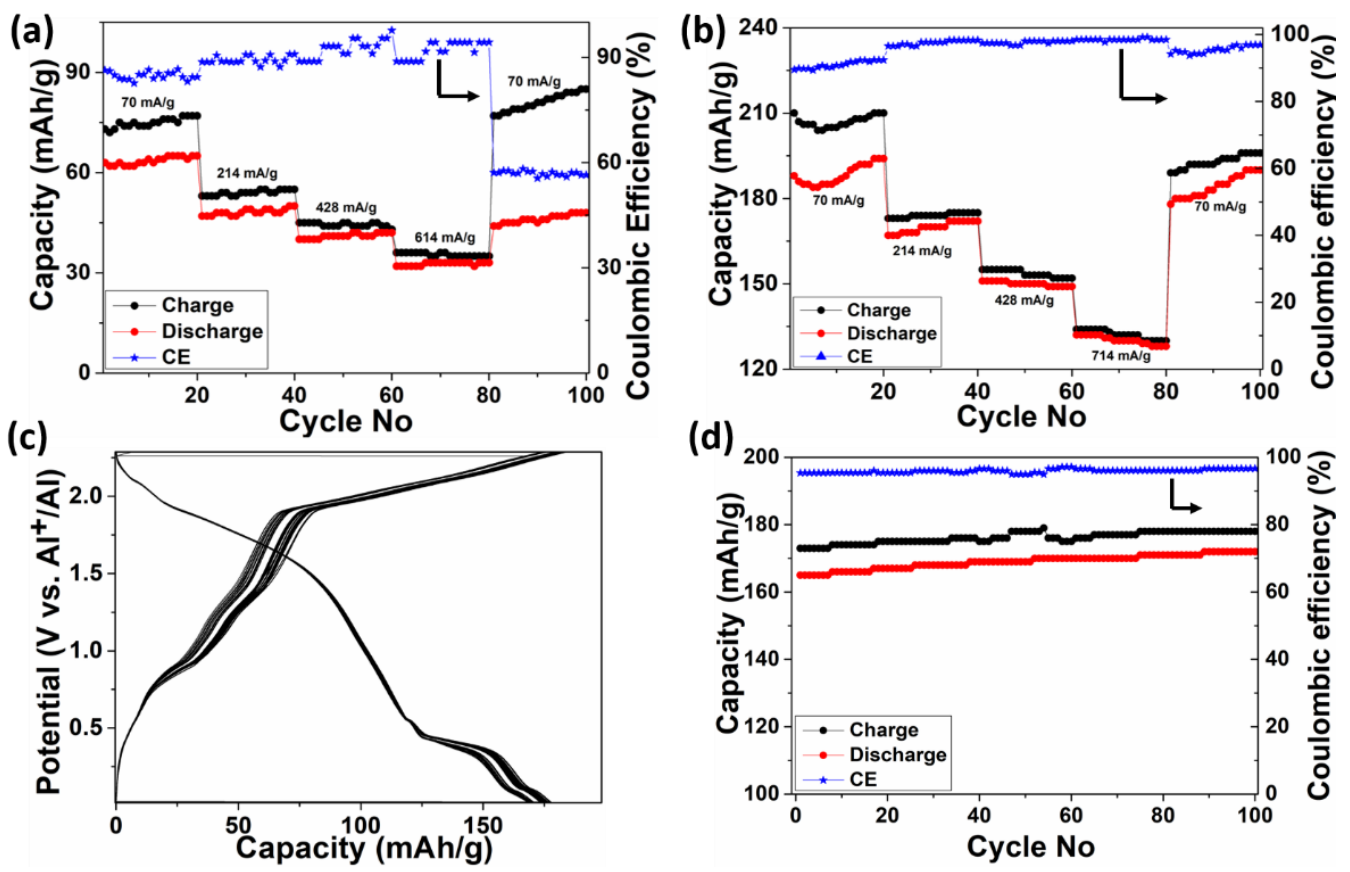

Fig. 3: Current rate performance of graphite (a) and (b) EG electrode at various current densities starting from $70 \mathrm{mAg}^{-1}$ to $714 \mathrm{mAg}^{-1}$; Charge-discharge profile and coulombic efficiency of EG for more than 100 cycles at $214 \mathrm{mAh} / \mathrm{g}$ (c and d, respectively).

In order to verify the structural resilience of the electrodes and their capacity to retain the electrochemical response, charge-discharge cycles at various current densities were performed. Both electrodes were cycled for 10 times at each step of current density, these ranging from 70 to $714 \mathrm{~mA} / \mathrm{g}$. From Figs. 3a and 3b, the $\mathrm{G}$ electrode had a 30\% drop in capacity (at $70 \mathrm{~mA} / \mathrm{g}$ ) whilst the EG showed only residual capacity loss $(<2 \%)$, when the current rate brought back to $70 \mathrm{~mA} / \mathrm{g}$. Furthermore, the capacity values attained by the EG were consistently higher with better and more stable coulombic efficiency.

To demonstrate the long cyclability of the EG electrode, more than 100 charge/discharge cycles were performed at a current density of $\sim 214 \mathrm{~mA} / \mathrm{g}$. As seen in Figs. 3c and $3 \mathrm{~d}$, the material exhibited, throughout, high stability and storage capacity $(\sim 172 \mathrm{mAh} / \mathrm{g})$ as well as a coulombic efficiency of $\sim 95 \pm 2 \%$. Notably, the specific capacity continuously increased from $\sim 188 \mathrm{mAh} / \mathrm{g}$ to $\sim 194 \mathrm{mAh} / \mathrm{g}$ (at current rate $70 \mathrm{~mA} / \mathrm{g}$ ). This is attributed to a 
larger number of aluminum chlorate anions that take part in the charge-discharge process as the cycling progresses and more of the intercalant diffuses to the core of the graphene layers. It is worth to note that the formation of dendrites was not observed on the $\mathrm{Al}$ anode, even after 100 cycles (Fig. S5).
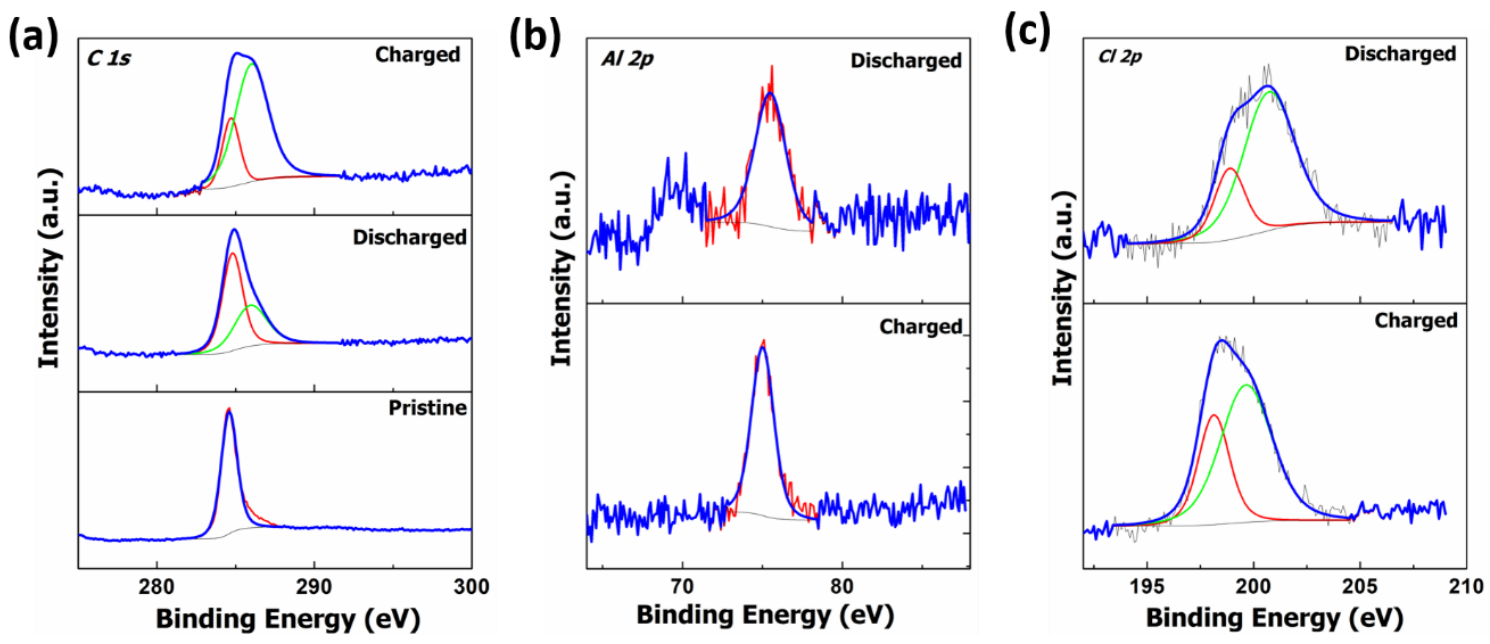

Fig. 4: XPS spectra of pristine, charged and discharged EG electrode. (a) C1s, (b) Al 2p and (c) $\mathrm{Cl} 2 \mathrm{p}$.

X-ray photoelectron spectroscopy (XPS) was carried out to probe the chemical nature of the $\mathrm{Al}$ species in the EG electrode's surface, in the charged and discharged states. Fig. 4a shows the $\mathrm{C} 1 s$ spectra of the pristine and the electrochemically treated samples, revealing that the peak at $284.6 \mathrm{eV}$ developed a higher energy shoulder upon charging. This additional peak, at $285.2 \mathrm{eV}$, indicates the electrochemical intercalation of the $\mathrm{Al}_{\mathrm{x}} \mathrm{Cl}_{\mathrm{y}}$ anions. ${ }^{14}$ While discharging the cell, the $\mathrm{C} 1 s$ peak partly reverted back to the binding energy characteristic of pristine graphite, most likely due to the anion's de-intercalation from the carbon (Fig. 4a). Analysis of the $\mathrm{Al} 2 p$ and $\mathrm{Cl} 2 p$ peaks (Figs. $4 \mathrm{~b}$ and $4 \mathrm{c}$ ) shows there is a slight change in their profiles after discharging. This can be the result of trapped or adsorbed chloroaluminate anions in the graphene layers. Of note, the presence of oxygen-containing functional groups in the 
exfoliated materials which was confirmed by the peak at $532.5 \mathrm{eV}$ in the survey XPS spectrum (Fig. S6).

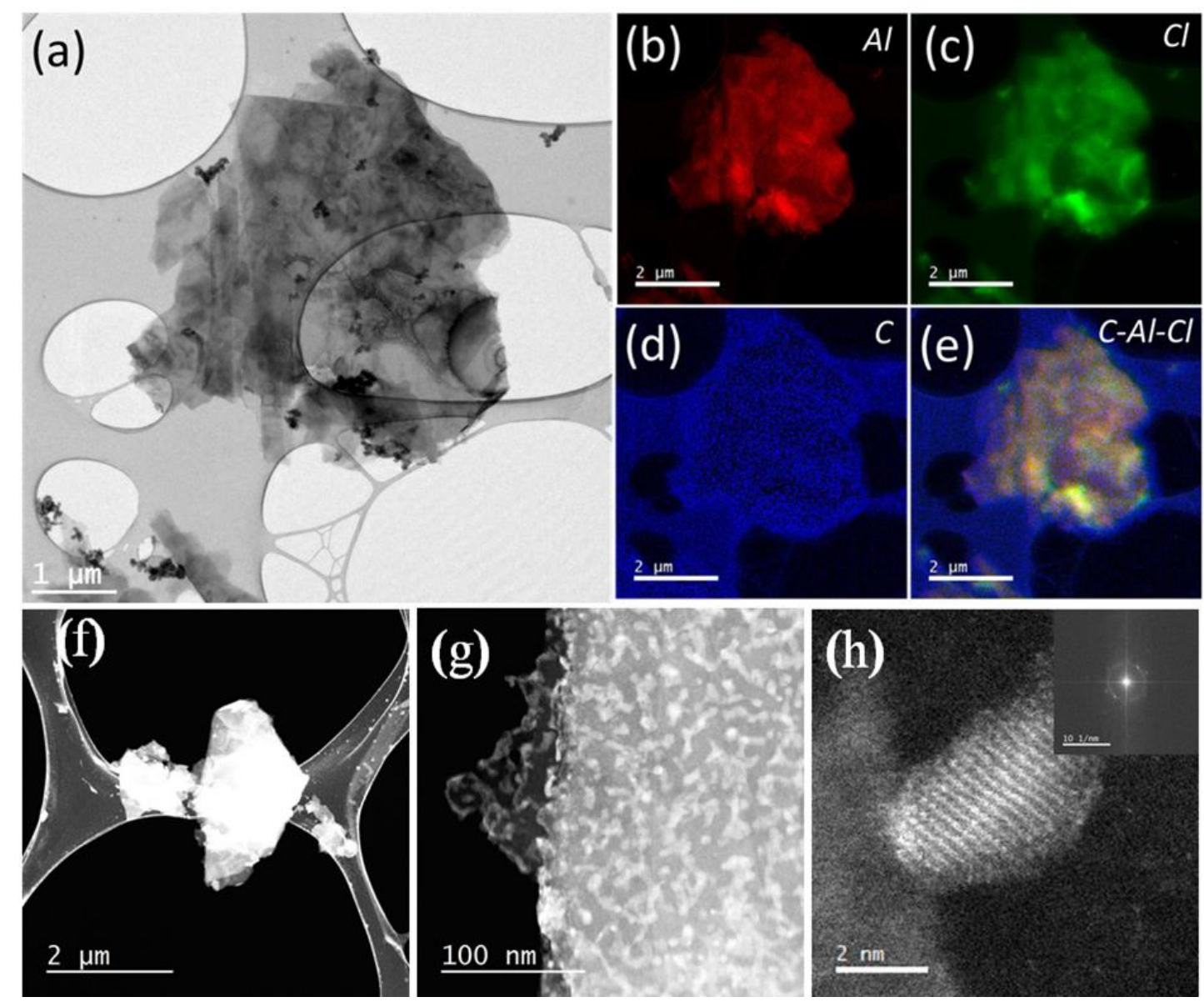

Fig. 5: EF-TEM analysis of EG electrode from first charged cathode. (a) A BF TEM image generated using a zero loss, (b) Al elemental generated by using an Al-L23 edge at an energy loss of $73 \mathrm{eV}$. (c) $\mathrm{Cl}$ elemental generated by using a Cl-L23 edge at an energy loss of $200 \mathrm{eV}$ (d) $\mathrm{C}$ elemental generated by using a $\mathrm{C}-\mathrm{K}$ edge at an energy-loss of $283 \mathrm{eV}$. (e) RGB superimposed image for C-Al-Cl. STEM acquired using Cs probe corrected Titan. (a) A large EG flakes with first charged cathode. (g) HADDF images showing presence of Al-Cl clusters in graphene skeleton. (h) HRTEM image of Al-Cl clusters (inset showing FFT pattern).

Energy filtered (EF-) TEM images of isolated flakes from the EG electrode were taken after the first charging cycle (Fig. 5). As per the zero-loss bright field TEM image in Fig. 5a, the jagged morphology, typical of graphitic flakes, was retained after the electrochemical procedure. However, several areas with darker contrast were observed, possibly denouncing the localization of pockets of heavier non-C elements. The elemental maps in Figs. $5 \mathrm{~b}$ to $5 \mathrm{~d}$ confirm the presence of $\mathrm{Al}$ and $\mathrm{Cl}$. The RGB superposed image provides further insight into 
the heterogeneity of the elemental dispersion, correlating well a higher concentration of $\mathrm{Al}$ and/or $\mathrm{Cl}$ with the darker contrast regions seen in Fig. 5a. Imaging of a second set of charged EG flakes identified randomly oriented and well-dispersed aggregates of nanoparticles on their surface (Figs. 5f to 5h). These nanoparticles have crystalline order (as attested in Fig. 5h and respective fast-Fourier transform, in inset) and are mainly composed of $\mathrm{Al}$ and $\mathrm{Cl}$ (elemental maps not shown).

To better understand the interaction of the chloroaluminate anions with the exfoliated material, first-principles calculations were carried out. The EG was modelled by grafting relevant oxygen-containing functional groups $(-\mathrm{O}$ and $-\mathrm{OH})$ onto the graphene layers. Various concentrations were considered, adding to an overall surface coverage of up to $\sim 6 \%$ (of the total number of $\mathrm{C}$ atoms in the layer). The plot in Fig. 6a illustrates how the interlayer distance of the EG changes as a function of the coverage with different functional groups. We observe the stacking of $\mathrm{EG}$ is not $\mathrm{AB}$, rather $\mathrm{AA}^{\prime}$ (which is also observed at various preparation condition of few layer graphene) $[39,40]$. To best match the interlayer spacing measured from HRTEM (Fig. S1) and account for the presence of oxygen-containing groups (as per the XPS analysis), an equitable mixture of $3.12 \%-\mathrm{O}$ and $3.12 \%-\mathrm{OH}$ was selected. Calculations of the electronic density of states (DOS) for each optimized EG structure revealed that the electrical conduction of the functionalized graphene shifts with increased molecular grafting (Fig. S7). When $\mathrm{AlCl}_{4}$ intercalation was considered (charged state), the DOS simulation predicted that the $3.12 \%$ compound EG material would show metal-like transport behavior (Fig. 6b). This contrasts with the analogous simulations made for $\mathrm{G}$ which indicate retention of semi-metal character, thereby supporting the observation of higher specific capacity for the EG electrodes. Placing chloroaluminate species between functionalized graphene layers not only increases the interlayer spacing but also leads to increased distortions of the in-plane arrangement of the carbon atoms. To match the experimental observations, the concentration of intercalated $\mathrm{AlCl}_{4}$ 
units was optimized to $1.56 \%$ (Fig. S8). Interestingly, a portion of the units bound covalently to the functional groups while others did not (Figs. 6c and 6d). As a result, different intercalated $\mathrm{AlCl}_{4}$ orientations and increased corrugation of the graphene were seen.
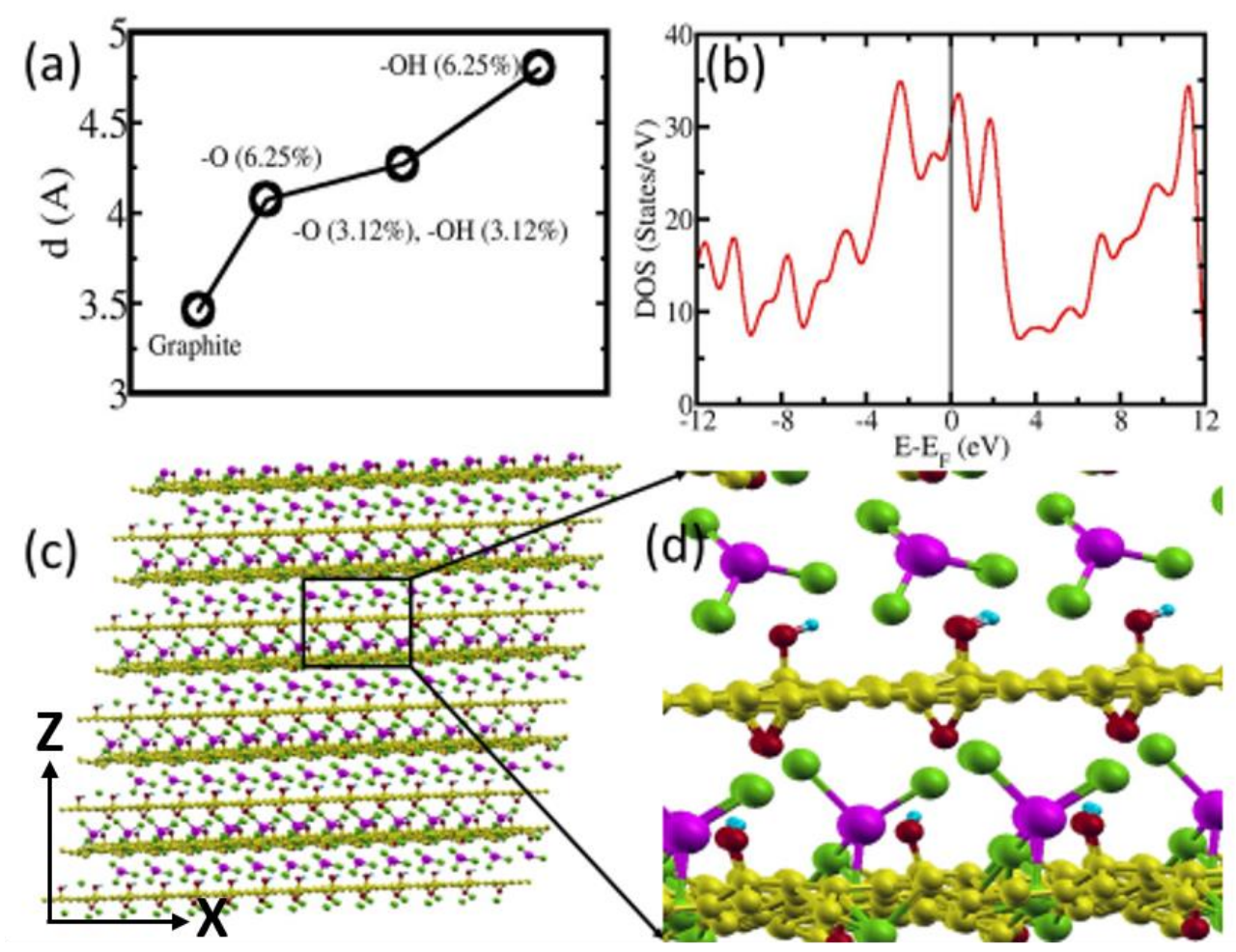

Fig. 6: (a) Average interlayer separation of graphite (G) and exfoliated graphite (EG); (b) Electronic density of states of charged EG; (c) Representative image of charged EG (Optimized structure from DFT) (d) Magnified image from fig. c.

Discussion

In the above, it was demonstrated that the EG offers enhanced electrochemical performance when compared to pristine graphite powder. The fact that the EG material is more crumpled and its graphene layers have larger interplanar distances is thought to promote enhanced dispersion of the liquid electrolyte on and into the carbon-based electrode [41]. Furthermore, the presence of oxygen-containing functional groups attached to the graphene layers contributes to increase the concentration of intercalated chloroaluminate anions. Some of these end up retained by covalent bonding (irreversible trapping) but this action may not be entirely disadvantageous as it appears to increase the conductivity of the compound material. 
The capacity figures herein reported compare well with those in the literature, as per Table 1. While variables such as current rate, type of electrolyte, etc., can make a direct comparison challenging the capacity value obtained in this work remains very interesting.

Table 1: Comparison of reported specific capacities of $\mathrm{Al}$ ion battery

\begin{tabular}{|c|c|c|c|}
\hline $\begin{array}{c}\text { Electrode } \\
\text { material }\end{array}$ & $\begin{array}{c}\text { Discharge capacity } \\
\text { at } 1^{\text {st }} \text { cycle, mAh/g }\end{array}$ & $\begin{array}{c}\text { Discharge capacity (number } \\
\text { of cycles), mAh/g }\end{array}$ & $\begin{array}{c}\text { Current rate, } \\
\mathrm{mA} / \mathrm{g}\end{array}$ \\
\hline $\begin{array}{c}\mathrm{V}_{2} \mathrm{O}_{5} \\
\text { nanowire[42] }\end{array}$ & 136 & $115(100)$ & 500 \\
\hline $\begin{array}{c}\mathrm{TiO}_{2} \text { nano- } \\
\text { leaves[43] }\end{array}$ & 107 & $40(10)$ & 10 \\
\hline graphite[44] & 110 & n.a. & 66 \\
\hline Graphite[45] & 260 & $254(300)$ & 100 \\
\hline FLG/Graphite[46] & 108 & n.a. & 100 \\
\hline $\begin{array}{c}\text { Graphite[47] } \\
\text { Graphite[48] }\end{array}$ & 102 & n.a. & 80 \\
\hline $\begin{array}{c}\text { This work (EG } \\
\text { electrode) }\end{array}$ & $\mathbf{1 6 6}$ & $50(600)$ & $\mathbf{2 1 4}$ \\
\hline
\end{tabular}

\section{Conclusion}

Employing graphene flakes derived from exfoliated graphite as an electrode material for Al-based batteries results in superior performance and stability when compared to pristine graphite. This is justified by the presence of functional groups that increase the interlayer spacing of graphene layers and assist in reversibly hosting chloroaluminate anions. While the results interpretation has been based in the intercalation phenomena, it is possible that surface charge storage mechanisms such as those found in supercapacitors may also contribute to the enhanced capacity here reported (e.g. via the grafted choroaluminate moieties).

\section{Conflicts of interest}

SPP and PMFJC are co-founders of the start-up company Graphene Crystal. 


\section{Acknowledgements}

The authors are grateful for funding from KAUST (BAS/1/1346-01-01). The assistance of KAUST Core Labs personnel is acknowledged.

\section{References}

[1] P. Miller, Johnson Matthey Tech., 59 (2015) 4.

[2] B. Scrosati, J. Garche, J. Power Sources, 195 (2010) 2419.

[3] E. Karden, S. Ploumen, B. Fricke, T. Miller, K. Snyder, J. Power Sources, 168 (2007) 2.

[4] Y.X. Wang, B. Liu, Q.Y. Li, S. Cartmell, S. Ferrara, Z.Q.D. Deng, J. Xiao, J. Power Sources, 286 (2015) 330.

[5] C.A. Mack, IEEE Transactions on Semiconductor Manufacturing, 24 (2011) 202.

[6] D.C. Bock, A.C. Marschilok, K.J. Takeuchi, E.S. Takeuchi, Electrochim. Acta, 84 (2012) 155.

[7] A. Patil, V. Patil, D.W. Shin, J.W. Choi, D.S. Paik, S.J. Yoon, Mater. Res. Bull., 43 (2008) 1913.

[8] S.W. Kim, D.H. Seo, X.H. Ma, G. Ceder, K. Kang, Adv. Energy Mater., 2 (2012) 710.

[9] E. Levi, Y. Gofer, D. Aurbach, Chem. Mater., 22 (2010) 860.

[10] J. Smajic, A. Alazmi, S.P. Patole, Pedro M.F.J. Costa, RSC Advances, 7 (2017) 39997.

[11] R. Thomas, G. Mohan Rao, J. Mater. Chem. A, 3 (2015) 274.

[12] X. Zhang, Y. Tang, F. Zhang, C.-S. Lee, Adv. Energy Mater., 6 (2016) 1502588.

[13] S. Wang, Z. Yu, J. Tu, J. Wang, D. Tian, Y. Liu, S. Jiao, Adv. Energy Mater., 6 (2016) 1600137.

[14] A. Eftekhari, P. Corrochano, Sustainable Energy \& Fuels, 1 (2017) 1246.

[15] Z.A. Zafar, S. Imtiaz, R. Razaq, S. Ji, T. Huang, Z. Zhang, Y. Huang, J.A. Anderson, J. Mater.Chem. A, 5 (2017) 5646.

[16] Q.F. Li, N.J. Bjerrum, J Power Sources, 110 (2002) 1. 
[17] M.C. Lin, M. Gong, B.G. Lu, Y.P. Wu, D.Y. Wang, M.Y. Guan, M. Angell, C.X. Chen, J. Yang, B.J. Hwang, H.J. Dai, Nature, 520 (2015) 325.

[18] W. Wang, B. Jiang, W.Y. Xiong, H. Sun, Z.S. Lin, L.W. Hu, J.G. Tu, J.G. Hou, H.M. Zhu, S.Q. Jiao, Sci Rep-Uk, 3 (2013) 1.

[19] P.R. Gifford, J.B. Palmisano, J. Electrochem. Soc., 135 (1988) 650.

[20] N. Jayaprakash, S.K. Das, L.A. Archer, Chem. Comm., 47 (2011) 12610.

[21] J.V. Rani, V. Kanakaiah, T. Dadmal, M.S. Rao, S. Bhavanarushi, J. Electrochem. Soc., 160 (2013) A1781.

[22] N.S. Hudak, J.Phys. Chem. C, 118 (2014) 5203.

[23] Y. Tang, L. Lu, H.W. Roesky, L. Wang, B. Huang, J. Power Sources, 138 (2004) 313.

[24] L.X. Geng, G.C. Lv, X.B. Xing, J.C. Guo, Chem. Mater., 27 (2015) 4926.

[25] Y. Matsuda, Y. ŌOuchi, H. Tamura, J. App. Electrochem., 4 (1974) 53.

[26] S. Licht, G. Levitin, C. Yarnitzky, R. Tel-Vered, Electrochem. Solid St., 2 (1999) 262.

[27] G. Levitin, C. Yarnitzky, S. Licht, Electrochem. Solid St., 5 (2002) A160.

[28] F. Endres, Chem. phys. chem., 3 (2002) 144.

[29] T. Jiang, M.J. Chollier Brym, G. Dubé, A. Lasia, G.M. Brisard, Surf. Coatings Tech., 201 (2006) 1.

[30] L.D. Reed, E. Menke, J. Electrochem. Soc., 160 (2013) A915.

[31] P.M.F.J.C. S. P. Patole, in, S. P. Patole, P. M. F. J. Costa, Expansion and exfoliation of graphite to form graphene, Patent, WO 2017125819 A1, 2017.

[32] P. Giannozzi, S. Baroni, N. Bonini, M. Calandra, R. Car, C. Cavazzoni, D. Ceresoli, G.L. Chiarotti, M. Cococcioni, I. Dabo, A. Dal Corso, S. de Gironcoli, S. Fabris, G. Fratesi, R. Gebauer, U. Gerstmann, C. Gougoussis, A. Kokalj, M. Lazzeri, L. Martin-Samos, N. Marzari, F. Mauri, R. Mazzarello, S. Paolini, A. Pasquarello, L. Paulatto, C. Sbraccia, S. 
Scandolo, G. Sclauzero, A.P. Seitsonen, A. Smogunov, P. Umari, R.M. Wentzcovitch, J. Phys-Condens. Mat., 21 (2009) 395502.

[33] J.P. Perdew, K. Burke, M. Ernzerhof, Phys. Rev. Let., 77 (1996) 3865.

[34] D. Vanderbilt, Phys. Rev. B, 41 (1990) 7892.

[35] H.J. Monkhorst, J.D. Pack, Phys. Rev. B, 13 (1976) 5188.

[36] M. Methfessel, A.T. Paxton, Phys. Rev. B, 40 (1989) 3616.

[37] C.R. Fell, D. Qian, K.J. Carroll, M. Chi, J.L. Jones, Y.S. Meng, Chem Mater, 25 (2013) $1621-1629$.

[38] M. Reynaud, M. Ati, B.C. Melot, M.T. Sougrati, G. Rousse, J.-N. Chotard, J.-M.

Tarascon, Electrochemistry Communications, 21 (2012) 77-80.

[39] J.K. Lee, S.C. Lee, J.P. Ahn, S.C. Kim, J.I.B. Wilson, P. John, J.Chem. Phy., 129 (2008).

[40] J.-K. Lee, J.-G. Kim, K.P.S.S. Hembram, Y.-I. Kim, B.-K. Min, Y. Park, J.-K. Lee, D.J. Moon, W. Lee, S.-G. Lee, P. John, Sci Rep-Uk, 6 (2016) 39624.

[41] J. Smajic, A. Alazmi, N. Batra, T. Palanisamy, D.H. Anjum, P.M.F.J. Costa, Small, 14 (2018) 1803584.

[42] S. Gu, H. Wang, C. Wu, Y. Bai, H. Li, F. Wu, Energy Storage Mater, 6 (2017) 9.

[43] Y.J. He, J.F. Peng, W. Chu, Y.Z. Li, D.G. Tong, J. Mater. Chem. A, 2 (2014) 1721.

[44] D.-Y. Wang, C.-Y. Wei, M.-C. Lin, C.-J. Pan, H.-L. Chou, H.-A. Chen, M. Gong, Y.

Wu, C. Yuan, M. Angell, Y.-J. Hsieh, Y.-H. Chen, C.-Y. Wen, C.-W. Chen, B.-J. Hwang, C.-

C. Chen, H. Dai, Nature Comm., 8 (2017) 14283.

[45] Y. Song, S. Jiao, J. Tu, J. Wang, Y. Liu, H. Jiao, X. Mao, Z. Guo, D.J. Fray, J. Mater.Chem. A, 5 (2017) 1282.

[46] A.S. Childress, P. Parajuli, J.Y. Zhu, R. Podila, A.M. Rao, Nano Energy, 39 (2017) 69. [47] Z. Li, B. Niu, Y. Liu, J. Li, F. Kang, Electrochim. Acta, 263 (2018) 68. 
[48] S. Wang, S. Jiao, W.-L. Song, H.-S. Chen, J. Tu, D. Tian, H. Jiao, C. Fu, D.-N. Fang, Energy Storage Mater, 12 (2018) 119. 